Editor's Note: These short reviews of recent JNeurosci articles, written exclusively by students or postdoctoral fellows, summarize the important findings of the paper and provide additional insight and commentary. If the authors of the highlighted article have written a response to the Journal Club, the response can be found by viewing the Journal Club at www.jneurosci.org. For more information on the format, review process, and purpose of Journal Club articles, please see http://jneurosci.org/content/ preparing-manuscript\#journalclub.

\title{
Unified and Separable Hippocampal Representations of Time and Space
}

\author{
- Iva K. Brunec \\ Department of Psychology, University of Toronto, Toronto, Ontario M5S 3G3, Canada, and Rotman Research Institute, Baycrest Health Sciences, Toronto, \\ Ontario M6A 2E1, Canada \\ Review of Salz et al.
}

\section{Introduction}

The integration of spatial and temporal information is crucial for efficient spatial navigation and episodic memory. Spatial coding relies on a joint representation of the environment by hippocampal place cells and entorhinal grid cells in rodents (Buzsáki and Moser, 2013). This notion is supported by evidence from human intracranial recordings (Miller et al., 2013) and neuroimaging and neuropsychological studies (Spiers and Barry, 2015; Moscovitch et al., 2016). More recently, cells coding for time elapsed in an interval (time cells) have also been reported in the rodent hippocampus (Pastalkova et al., 2008; MacDonald et al., 2011) and entorhinal cortex (Kraus et al., 2015).

A key question is how this temporal code is supported by ensemble dynamics of hippocampal subfields. Time cells had previously been reported only in CA1 of the hippocampus, consistent with the notion that CA1 neurons code for sequential

Received Sept. 12, 2016; revised 0ct. 21, 2016; accepted 0ct. 25, 2016.

I.K.B. is supported by Alzheimer Society Canada doctoral award. The author is grateful to Drs. Morris Moscovitch and Morgan Barense for feedback and continued support.

The authors declare no competing financial interests.

Correspondence should be addressed to Iva K. Brunec, Department of Psychology, University of Toronto, 4th Floor, Sidney Smith Hall, 100 St. George Street, Toronto, Ontario M5S 3G3, Canada. E-mail: Iva.kristlbrunec@mail.utoronto.ca.

DOI:10.1523/JNEUROSCI.2860-16.2016

Copyright $\odot 2016$ the authors $\quad 0270-6474 / 16 / 3612293-03 \$ 15.00 / 0$ events (Farovik et al., 2010; Allen et al., 2016) and that connections between the medial entorhinal cortex (MEC) and CA1 support associations across temporal intervals (Kitamura et al., 2014). In a recent issue of The Journal of Neuroscience, Salz et al. (2016) reported evidence of time cells in CA3, taking an important step toward understanding how space and time are represented by the hippocampus.

Salz et al. (2016) recorded from cells in CA1 and CA3 while rats alternated between running on a treadmill and traversing a track. Temporal coding by time cells was assessed during treadmill running when the rats' spatial position remained stable, whereas spatial coding by place cells was assessed during track traversal. Salz et al. (2016) found that time cell coding in CA3 closely resembled that in CA1. Similar numbers of neurons encoded time in both subfields, with comparable peak firing rates and mean field width (duration coded by each cell). This resembled the findings for spatial coding, where similar numbers of CA1 and CA3 neurons were place cells, with comparable field widths (distance coded by each cell), but CA3 neurons showed significantly higher peak firing rates. In both subfields, however, cell field widths were significantly larger during temporal relative to spatial coding when time was converted to distance traversed, highlighting less precise temporal than spatial coding resolution.
Temporal field resolution progressively decreased in both subfields throughout the elapsed interval, replicating past findings (MacDonald et al., 2011).

Time and space therefore appear to be encoded similarly by CA1 and CA3. This finding, however, raises the fundamental question of how CA1 and CA3 might differ. Do time and place cells in CA1 and CA3 serve different functional purposes, and what are the conditions in which differences between CA1 and CA3 temporal and spatial codes might be observed? Predictions can be made about the differences in the functional purpose of temporal coding in CA1 and CA3 based on their respective connectivity within the entorhinal-hippocampal circuit.

\section{Subfield-specific cortical interactions} and coding dynamics

CA1 receives input from CA3 and layer III of the MEC, whereas CA3 receives input from layer II of the MEC via the dentate gyrus (Fig. 1). Past research showed that removing the connection between layer III of the MEC and CA1 degraded spatial coding in CA1 (Brun et al., 2008), although it was preserved in CA3. In line with this observation, it may be predicted that disrupting the connection between the MEC and CA1 would result in decreased resolution of temporal coding in CA1, without affecting temporal coding in CA3. CA1 is thought to act as a compar- 


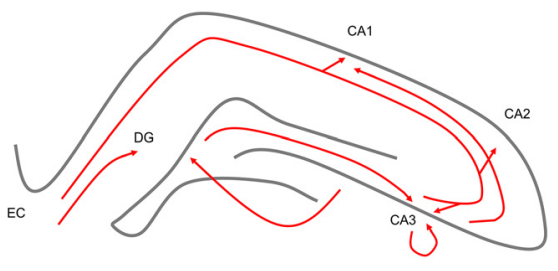

Figure 1. Known direct and indirect connections between the EC and hippocampal subfields, and between individual subfields (based on Knierim, 2015). CA1 gets input from layer III of the MEC, whereas CA3 gets input from layer II. CA3 passes information on to CA1 (directly and via $C A 2$ ). The recurrent connectivity within CA3 is also illustrated. It would be important to evaluate the specific impact of destroying MEC-CA1 versus MEC-CA3 pathways on temporal coding, both in terms of immediate tracking of space and time in CA1 and long-term stored representations in CA3.

ator between current input from the MEC and representations of past experience stored in DG-CA3 (Vinogradova, 2001; Lee et al., 2004). The hypothesis by Salz et al. (2016) that temporal input to the hippocampus originates from the MEC may be extended, such that lesions to the MEC-CA1 pathway may conceivably preserve online temporal coding in CA3 but abolish comparisons between incoming MEC input with stored duration representations. For example, if an animal with a lesion to its CA1 was exposed to two different treadmill durations, normal time cell activity while running would be predicted in CA3, but the animal would later be unable to discriminate between the two experiences.

\section{Stability and retrieval of spatial and temporal representations}

The issue of stored temporal and spatial representations leads to a second important question about the difference in hippocampal temporal and spatial codes: the stability, or robustness of reinstatement, of spatial versus temporal fields. As Salz et al. (2016) report, place fields are consistently present across tasks, but time fields are not. Their compelling explanation is that space is inherently structured, but time is not. This notion is further supported by the finding that temporal coding resolution decreases over the course of an interval because relatively few temporal cues are present, whereas spatial resolution is maintained because of the constant stream of spatial cues. Imposing different temporal structures on a task would provide crucial insight into whether temporal fields might emerge and how stable they would be.

Previous research has shown that CA1 time cells "re-time" for different treadmill running speeds (Kraus et al., 2015). The properties of re-timing would be expected to differ between CA1 and CA3 based on differences reported in spatial coding. Specifically, when relatively minor environmental cues are altered, the population spatial code tends to remain more coherent in CA3, relative to CA1. When large-scale spatial landmarks are changed, however, the representation in CA3 rapidly shifts to a new neuronal population but scales linearly with the degree of change in CA1 (Guzowski et al., 2004). Assuming that hippocampal spatial and temporal coding shares similar dynamics, these tendencies should also be reflected in the remapping of temporal information. If the temporal structure of two experiences was very different (e.g., highly different treadmill run durations), a drastic shift should be observed in the CA3 neuronal population carrying a particular temporal code, whereas similar temporal structure should bias CA3 toward maintaining the same neuronal ensemble between the two treadmills. Combining this notion of firing field stability with the connectivity of the two subfields opens new avenues for research into multiday dynamics, as pointed out by Salz et al. (2016).

\section{Temporally structured experiences}

Many experiences beyond spatial navigation follow a clear temporal structure in terms of both their duration and the order in which elements occur. We structure our lives in time, possibly as much as in space. Recent human neuroimaging studies have started uncovering hippocampal involvement in memory for sequential events (Hsieh et al., 2014; DuBrow and Davachi, 2016) and tracking the duration of individual events (Barnett et al., 2014).

The resolution of neuroimaging studies does not yet allow us to make conclusive claims about the flow of information and how duration and sequence might be integrated in the hippocampus. A recent study, however, provided evidence using fMRI in humans that CA1, but not CA3/ DG, processes the sequence (temporal order) of events (Wang and Diana, 2016). Sequence information mediated by CA1 thus appears to rely on a direct projection from layer III of the EC and input of stored representations from CA3. In contrast to duration processing, which Salz et al. (2016) found to be processed similarly in the two subfields, disambiguating the order in which elements occurred close in time might be more CA1-dependent. CA1, but not CA3, was found to carry information about sequence over longer periods of time (Farovik et al., 2010). An intriguing possibility based on the evidence presented here is that stored temporal representations in CA3 may be associated over time through a joint MEC-CA1 signal into a sequence of events. Sequential coding necessarily involves a relation between the current item and some information stored in memory, so CA1 is implicated. Conversely, temporal duration coding may be accomplished without reference to other events, at least for relatively short durations, and may therefore rely on both CA1 and CA3. The encoding of sequence information in CA1 may result, therefore, from the integration of sequential temporal firing fields, which are then compared by CA1 so their order can be established.

In conclusion, evidence for similar temporal coding in CA1 and CA3 by Salz et al. (2016) provides important insight into the dynamics of hippocampal subfields in the processing of space and time, and raises a number of new questions. Evaluating the conditions under which CA1 and CA3 differ in their temporal coding properties would elucidate the flow of temporal information in the hippocampal-entorhinal circuit. Identifying subfield-specific patterns of activity for duration and sequence would bring us closer to understanding how stored representations are compared with ongoing temporal processing. Finally, extending this line of work to neuroimaging in humans would enable the investigation of how subepisodes with individual durations are segmented, yet bound into the flow of everyday experience.

\section{References}

Allen TA, Salz DM, Mckenzie XS, Norbert X, Fortin J (2016) Behavioral/cognitive nonspatial sequence coding in CA1 neurons. 36:1547-1563.

Barnett AJ, O'Neil EB, Watson HC, Lee AC (2014) The human hippocampus is sensitive to the durations of events and intervals within a sequence. Neuropsychologia 64:1-12. CrossRef Medline

Brun VH, Leutgeb S, Wu HQ, Schwarcz R, Witter MP, Moser EI, Moser MB (2008) Impaired spatial representation in CA1 after lesion of direct input from entorhinal cortex. Neuron 57:290-302. CrossRef Medline

Buzsáki G, Moser EI (2013) Memory, navigation and theta rhythm in the hippocampalentorhinal system. Nat Neurosci 16:130-138. CrossRef Medline

DuBrow S, Davachi L (2016) Temporal binding within and across events. Neurobiol Learn Mem 134:107-114. CrossRef Medline

Farovik A, Dupont LM, Eichenbaum H (2010) Distinct roles for dorsal CA3 and CA1 in memory for sequential nonspatial events. Learn Mem 17:12-17. CrossRef Medline

Guzowski JF, Knierim JJ, Moser EI (2004) En- 
semble dynamics of hippocampal regions CA3 and CA1. Neuron 44:581-584. CrossRef Medline

Hsieh LT, Gruber MJ, Jenkins LJ, Ranganath C (2014) Hippocampal activity patterns carry information about objects in temporal context. Neuron 81: 1165-1178. CrossRef Medline

Kitamura T, Pignatelli M, Suh J, Kohara K, Yoshiki A, Abe K, Tonegawa S (2014) Island cells control temporal association memory. Science 343:896-901. CrossRef Medline

Knierim JJ (2015) Primer: the hippocampus. Curr Biol 25:R1116-R1121.

Kraus BJ, Brandon MP, Robinson RJ 2nd, Connerney MA, Hasselmo ME, Eichenbaum $\mathrm{H}$ (2015) During running in place, grid cells integrate elapsed time and distance run. Neuron 88:578-589. CrossRef Medline

Lee I, Yoganarasimha D, Rao G, Knierim JJ (2004) Comparison of population coherence of place cells in hippocampal subfields CA1 and CA3. Nature 430:456-459. CrossRef Medline

MacDonald CJ, Lepage KQ, Eden UT, Eichenbaum H (2011) Hippocampal "time cells" bridge the gap in memory for discontiguous events. Neuron 71: 737-749. CrossRef Medline

Miller JF, Neufang M, Solway A, Brandt A, Trippel M, Mader I, Hefft S, Merkow M, Polyn SM, Jacobs J, Kahana MJ, Schulze-Bonhage A (2013) Neural activity in human hippocampal formation reveals the spatial context of retrieved memories. Science 342:1111-1114. CrossRef Medline

Moscovitch M, Cabeza R, Winocur G, Nadel L (2016) Episodic memory and beyond: the hippocampus and neocortex in transformation. Annu Rev Psychol 67:105-134. CrossRef Medline

Pastalkova E, Itskov V, Amarasingham A, Buzsáki
G (2008) Internally generated cell assembly sequences in the rat hippocampus. Science 321:1322-1327. CrossRef Medline

Salz DM, Tiganj Z, Khasnabish S, Kohley A, Sheehan D, Howard MW, Eichenbaum H (2016) Time cells in hippocampal area CA3. J Neurosci 36:7476-7484. CrossRef Medline

Spiers HJ, Barry C (2015) Neural systems supporting navigation. Curr Opin Behav Sci 1:47-55. CrossRef

Vinogradova OS (2001) Hippocampus as comparator: role of the two input and two output systems of the hippocampus in selection and registration of information. Hippocampus 11: 578-598. CrossRef Medline

Wang F, Diana RA (2016) Temporal context processing within hippocampal subfields. Neuroimage 134:261-269. CrossRef Medline 